\title{
Statistical optimization of dithranol-loaded solid lipid nanoparticles using factorial design
}

\author{
Makarand Suresh Gambhire ${ }^{1, *}$, Mangesh Ramesh Bhalekar ${ }^{2}$, Vaishali Makarand Gambhire ${ }^{3}$
}

${ }^{1}$ Department of Pharmaceutical Sciences, Jaipur National University, Jagatpura, Jaipur, India,

${ }^{2}$ Department of Pharmaceutics, AISSMS College of Pharmacy, Pune, India, ${ }^{3}$ Department of Pharmaceutics, Sinhgad college of Pharmacy, Vadgaon (Bk.), Pune, India

\begin{abstract}
This study describes a $3^{2}$ full factorial experimental design to optimize the formulation of dithranol (DTH) loaded solid lipid nanoparticles (SLN) by the pre-emulsion ultrasonication method. The variables drug: lipid ratio and sonication time were studied at three levels and arranged in a $3^{2}$ factorial design to study the influence on the response variables particle size and \% entrapment efficiency (\%EE). From the statistical analysis of data polynomial equations were generated. The particle size and \%EE for the 9 batches (R1 to R9) showed a wide variation of 219-348 nm and 51.33-71.80\%, respectively. The physical characteristics of DTH-loaded SLN were evaluated using a particle size analyzer, differential scanning calorimetry and X-ray diffraction. The results of the optimized formulation showed an average particle size of $219 \mathrm{~nm}$ and entrapment efficiency of $69.88 \%$. Ex-vivo drug penetration using rat skin showed about a 2-fold increase in localization of DTH in skin as compared to the marketed preparation of DTH.
\end{abstract}

Uniterms: Solid lipid nanoparticles. Homogenization. Ultrasonication. $3^{2}$ factorial design. Dithranol.

Este estudo descreve o planejamento factorial $3^{2}$ para otimizar a formulação de nanopartículas lipídicas sólidas (SLN) carregadas com ditranol (DTH) pelo método da ultrassonificação pré-emulsão. As variáveis como proporção de fármaco:lipídio e o tempo de sonicação foram estudados em três níveis e arranjados em planejamento fatorial $3^{2}$ para estudar a influência nas variáveis de resposta tamanho de partícula e eficiência percentual de retenção do fármaco (\%EE). Pela análise estatística, geraram-se equações polinomiais. O tamanho da partícula e a \%EE para os 9 lotes (R1 a R9) mostraram ampla variação, respectivamente, $219-348 \mathrm{~nm}$ e $51,33-71,80 \%$. As características físicas das SLN carregadas com DTN foram avaliadas utilizando-se analisador de tamanho de partícula, calorimetria de varredura diferencial e difração de raios X. Os resultados da formulação otimizada mostraram tamanho médio de partícula de 219 nm e eficiência de retenção do fármaco de 69,88\%. A penetração ex vivo do fármaco utilizando pele de rato mostrou aumento de, aproximadamente, duas vezes na localização de DTH na pele, comparativamente à preparação de DTH comercializada.

Unitermos: Nanopartículas lipídicas sólidas. Homogeneização. Ultrasonicação. Planejamento fatorial. Ditranol.

\section{INTRODUCTION}

Solid lipid nanoparticles (SLN) were developed at the beginning of the 1990s as an alternative carrier system to the existing traditional carriers, such as emulsions, liposomes and polymeric nanoparticles (Müller et al., 1995). Solid lipid nanoparticles (SLN) are the new generation of

\footnotetext{
*Correspondence: M. S. Gambhire. Sinhgad College of Pharmacy, S. No. 44/1, Vadgaon (Bk.), Off. Sinhgad Road, Pune - 411041 - India. Email: makarandgambhire@gmail.com
}

nanoparticulate active substance vehicles and are attracting major attention as novel colloidal drug carriers for topical use. Small lipid vesicles in the range of nanometers have advantages, but avoid the disadvantages, of other colloidal carriers (Utreja, Jain, 2001). Compared with polymeric nanoparticles, SLN have lower toxicity because of the absence of solvents in the production process and also relatively low cost excipients. SLN offer combined advantages such as controlled release, biodegradable, negligible skin irritation and protection of active compounds. (Müller, Mäder, Gohla, 2000; Sylvia, Müller, Wissing, 2003). The 
major advantage of SLN is the possibility of production on an industrial scale (Müller, Lippacher, Gohla, 2000). The lipids which are used in making these carriers have an approved status, offer low systemic toxicity and also low cytotoxicity (Müller, et al., 1997). Moreover, the small particle size of SLN ensure close contact with the stratum corneum (SC), thus increasing penetration of encapsulated active agent into the skin (Mei et al., 2003).

SLN have been reported to improve the photo stability and skin permeation of tretinoin (Shah, et al., 2007), provide a good skin targeting effect and constitute a promising carrier for topical delivery of penciclovir $(\mathrm{Lv}$, et al., 2009) and podophyllotoxin (Chen, et al., 2006), as well as reduce skin irritation on topical application (Maia, et al., 2000; Sivaramakrishnan, et al., 2004).

Psoriasis is one of the most common human skin diseases and is considered to have key genetic underpinnings. It is characterized by excessive growth and aberrant differentiation of keratinocytes (Lowes, Bowcock, Krueger, 2007). Dithranol or Anthralin is a hydroxyanthrone, anthracene-derivative medicine applied to the skin of individuals with psoriasis, exhibiting both anti-proliferative and anti-inflammatory properties. Dithranol accumulates in mitochondria, resulting in a reduction of adenosine triphosphatase (ATP) synthesis, which leads to inhibition of DNA replication and repair and hence slows the excessive cell division that occurs in psoriatic plaques (Gerritsen, 2007). In addition, modification of DNA bases and inhibition of various enzymes have also been described. Epidermal calmodulin has been reported to be elevated in psoriasis. Dithranol was demonstrated to be a potent competitive antagonist of calmodulin. (Tucker et al., 1986). SLN appears to be an interesting vehicle for topical administration of DTH (Carlotti et al., 2009). SLN could protect DTH from degradation caused by UVA irradiation.

The objective of this study was to develop a mathematical model using $3^{2}$ experimental design in order to deduce the adequate conditions for preparation of DTHloaded SLN with desired characteristics able to improve the localization of DTH in skin. Ex-vivo penetration and localization of the optimized formulations with maximum drug entrapment efficiency and minimum particle size were also examined.

\section{MATERIAL AND METHODS}

\section{Material}

Compritol 888 ATO was obtained as a gift sample from Gattefosse (France). Tween 80, Span 60, glyceryl monostearate (GMS) and poloxamer 407 were provided by
LOBA CHEMIE, India. Dithranol was donated by Glenmark, Washi, Mumbai (India). All other chemicals were of reagent grade and used without further purification.

\section{Preparation of SLN}

SLN were prepared by pre-emulsion followed by the ultrasonication method (Fang, et. al., 2008). Briefly, lipid phase consisted of dithranol, Compritol 888 ATO and Span $60(3 \% \mathrm{w} / \mathrm{v})$ maintained at $70^{\circ} \mathrm{C}$. An aqueous phase was prepared by dissolving poloxamer $407(3 \% \mathrm{w} / \mathrm{v})$ in distilled water (sufficient to produce $50 \mathrm{ml}$ of preparation) and heated to the same temperature as oil phase. Hot aqueous phase was added to oil phase and homogenization was carried out at a temperature of $70^{\circ} \mathrm{C}$ using an Omni TH homogenizer (Make Omni USA) at $46564.7 \times \mathrm{g}$ for 3 min. Coarse hot oil in water emulsion thus obtained was subjected to further size reduction using an ultrasonicator (make Sonic VCX 750, USA) for 10-30 min.

\section{Experimental design and statistical analysis}

Most formulation studies involve variation of one factor at a time, keeping other factors constant. Factorial design enables all factors to be varied simultaneously, allowing quantification of the effects caused by independent variables and interactions between them. In this study, a $3^{2}$ full factorial experimental design was introduced to optimize the formulation of nanoparticles. Initial studies were undertaken to decide on the excipients and their levels in the experimental design.

The choice of lipid was made on the basis of solubility and partitioning of dithranol in the lipid. Aqueous phase surfactant and lipid phase surfactant were selected on the basis of stability of dispersion prepared by using different surfactants.

In order to optimize the preparation of formulations, the drug: lipid ratio (X1) and sonication time (X2) were chosen as independent variables. These two factors that might affect the nanoparticle formulation and three levels of each factor were selected (Table I) and arranged according to a $3^{2}$ full factorial experimental table (Table II).

TABLE I - Independent variables and their selected levels for nanoparticles formulation

\begin{tabular}{lccc}
\hline Factor & \multicolumn{3}{c}{ Coded level } \\
& -1 & 0 & +1 \\
\hline Drug: lipid ratio $\left(\mathrm{X}_{1}\right)$ & $1: 3$ & $1: 5$ & $1: 7$ \\
Sonication time $\left(\mathrm{X}_{2}\right)($ min. $)$ & 10 & 20 & 30 \\
\hline
\end{tabular}


TABLE II - A $3^{2}$ Full factorial experimental design layout

\begin{tabular}{lcc}
\hline Formulation Code & \multicolumn{2}{c}{ Coded Factor Level } \\
& Factor 1 & Factor 2 \\
\hline $\mathrm{R}_{1}$ & -1 & -1 \\
$\mathrm{R}_{2}$ & 0 & -1 \\
$\mathrm{R}_{3}$ & 1 & -1 \\
$\mathrm{R}_{4}$ & -1 & 0 \\
$\mathrm{R}_{5}$ & 0 & 0 \\
$\mathrm{R}_{6}$ & 1 & 0 \\
$\mathrm{R}_{7}$ & -1 & 1 \\
$\mathrm{R}_{8}$ & 0 & 1 \\
$\mathrm{R}_{9}$ & 1 & 1 \\
\hline
\end{tabular}

\section{Evaluation of solid lipid nanoparticles}

\section{Particle size analysis}

The particle size analysis of the formulations was performed using a Malvern Mastersizer 2000 MS device (Malvern Instruments, Worcestershire, UK) and laser diffraction with a beam length of $2.40 \mathrm{~mm}$, range lens of $300 \mathrm{RF} \mathrm{mm}$, at $14.4 \%$ obscuration. The mean diameter of each batch is recorded in Table III.

\section{Entrapment efficiency}

For determination of entrapment in SLNs, the drug loaded lipid nanoparticles were separated from free drug by ultra-centrifugation (Beckmann Instruments, Italy) at about $158476.5 \times \mathrm{g}$. Free drug, determined spectrophotometrically from the added drug, remained unentrapped in supernatant liquid which was obtained after ultra-centrifugation. The collected samples were added in chloroform and warmed to dissolve completely, and then extracted with dimethyl formamide (DMF) which dissolved only dithranol. The solution was filtered, diluted with methanol and dithranol content determined spectrophotometrically.

EE was calculated according to the following equation:

$$
\mathrm{EE} \%=\frac{\text { Amount of entrapped drug in SLN }}{\begin{array}{c}
\text { Amount of entrapped drug in SLN } \\
\text { and free drug in dispersion }
\end{array}} \times 100
$$

\section{Differential Scanning Calorimetry (DSC) study}

Differential Scanning Calorimetry (DSC) was performed on a Mettler-Toledo DSC $821^{\mathrm{e}}$ (Columbus, $\mathrm{OH}$ ) instrument, and an empty standard aluminum pan was used as reference. DSC scans were recorded at a heating rate of $10^{\circ} \mathrm{C} / \mathrm{min}$ in a temperature range of $30-300^{\circ} \mathrm{C}$. DSC measurements were carried out on pure compritol 888 ATO and dithranol as bulk material and SLN loaded with dithranol.

\section{$X$-ray diffraction}

$\mathrm{X}$-ray scattering measurements were carried out with a Philips PAN analytical expert PRO X-ray diffractometer 1780. The samples were irradiated with mono-chromatized $\mathrm{CuKa}$ radiation and analyzed between $2-80^{\circ} \mathrm{C} 2 \varnothing$. The patterns were collected with voltage of $30 \mathrm{kV}$ and current of $30 \mathrm{~mA}$, respectively. The scanning rate $(2 \varnothing / \mathrm{min})$ was set at $10^{\circ} \mathrm{C} / \mathrm{min}$.

Fourier Transmission Infrared Spectroscopy (FTIR) studies

A Jasco FTIR spectrophotometer (Jasco FTIR- 401, Japan) was used for infrared analysis of samples. About 1-2 mg of sample was mixed with dry potassium bromide and the samples were examined at transmission mode over a wave number range of 4000 to $400 \mathrm{~cm}^{-1}$. FTIR studies were carried out on pure compritol 888 ATO and dithranol as bulk material and SLN loaded with dithranol.

\section{Ex-vivo skin penetration studies}

Ointment containing DTH-loaded SLN was prepared with white soft paraffin. Ointment containing plain DTH (marketed formulation) was acquired from the market. Ex-vivo skin penetration studies of DTH ointment were performed with rat skin (Liu, et al., 2007; Shah, et al., 2007; Lv, et al., 2009) using Franz diffusion cell. Rat skin was taken from the abdominal region, after removing hair and subcutaneous fat tissue, by punching out a disc of approximately $2.5-\mathrm{cm}^{2}$ in area. This slice was mounted on the Franz diffusion cell. Phosphate buffer ( $\mathrm{pH}$ 7.4) served as receptor fluid. A small quantity $(0.1 \mathrm{~g})$ of the ointment was applied to the skin surface. Serial sampling was performed at specified time intervals $(1,2,3,4,5,6,7,8,9,10,12$ hours $)$ by removing the contents of the receptor compartment and replacing it with fresh medium. The samples were analyzed using UV-VIS spectrophotometer (Shimadzu UV $1800)$ and mean cumulative amount diffused Q $\left(\mathrm{mg} / \mathrm{cm}^{2}\right)$ at each sampling time point was calculated. At the end of 12 hours, the amount of drug in the receptor compartment, the drug remaining on the skin, and the drug concentration in the skin was determined by extraction into a suitable solvent followed by spectrophotometric analysis using an UV-VIS spectrophotometer.

\section{RESULTS AND DISCUSSION}

\section{Experimental design and statistical analysis}

The objective of this study was to prepare solid lipid nanoparticles of dithranol by pre-emulsion ultrasonication method and to optimize the effects of formulation variables on response parameters. Based on preliminary 
studies, compritol 888 ATO, Span 60 and Poloxamer 407 were chosen as lipid, lipid phase surfactant and aqueous phase surfactant respectively. Drug:lipid ratio and sonication time were selected as variables and entrapment efficiency and particle size as response parameters. A $3^{2}$ full factorial design was selected as it helps study the effect on response parameters by changing both variables simultaneously with a minimum number of experimental runs.

The particle size and EE for the 9 batches (R1 to R9) showed a wide variation 219-348 $\mathrm{nm}$ and 51.33-71.08\%, respectively (Table III). The data clearly indicated strong dependence of response variables on the selected independent variables.

TABLE III - Values of particle size and entrapment efficiency of DTH-loaded SLN $\left(R_{1}-R_{9}\right)$ as per full factorial design

\begin{tabular}{lcc}
\hline Formulation code & Particle size $(\mathrm{nm})$ & \% EE \\
\hline $\mathrm{R}_{1}$ & 339 & 51.33 \\
$\mathrm{R}_{2}$ & 348 & 54.8 \\
$\mathrm{R}_{3}$ & 342 & 70.3 \\
$\mathrm{R}_{4}$ & 249 & 56.05 \\
$\mathrm{R}_{5}$ & 263 & 57.5 \\
$\mathrm{R}_{6}$ & 319 & 69.5 \\
$\mathrm{R}_{7}$ & 219 & 69.88 \\
$\mathrm{R}_{8}$ & 247 & 60.98 \\
$\mathrm{R}_{9}$ & 285 & 71.80 \\
\hline
\end{tabular}

In order to quantify the effect of formulation variables on the response parameters, it was necessary to construct a mathematical model which would help in predicting values of response parameters at any selected values of formulation variables within the boundaries of the design. It may be the case that the levels of formulation variables which are intermediate between the selected levels yield optimum formulation. Design Expert 7.1 software was used to generate a mathematical model for each response parameter and the subsequent statistical analysis.

The coefficients of the polynomial equations generated using MLRA (Design expert 7.1) for particle size and $\%$ EE of DTH-loaded SLN dispersion studied are listed in (Table IV) along with the values of $\mathrm{r}^{2}$. Five coefficients (a to e) were calculated with $\mathrm{k}$ as the intercept.

$\mathrm{Y}=k+a \mathrm{X}_{1}+b \mathrm{X}_{2}+c \mathrm{X}_{1} \mathrm{X}_{2}+d \mathrm{X}_{1}^{2}+e \mathrm{X}_{2}^{2}$

The equation was used to obtain estimates of the responses at various factor combinations, where the optimum
TABLE IV - Values of coefficients for polynomial equations and $\mathrm{r}^{2}$ for various response variables of DTH-loaded SLN

\begin{tabular}{lcc}
\hline $\begin{array}{l}\text { Coefficient } \\
\text { code }\end{array}$ & \multicolumn{2}{c}{$\begin{array}{c}\text { Polynomial coefficient values for } \\
\text { response variables }\end{array}$} \\
\hline $\mathrm{k}$ & Particle size & Entrapment efficiency \\
$\mathrm{a}$ & +272.89 & +56.32 \\
$\mathrm{~b}$ & +23.17 & +5.72 \\
$\mathrm{c}$ & -46.33 & +4.37 \\
$\mathrm{~d}$ & +15.75 & -4.26 \\
$\mathrm{e}$ & +6.17 & +7.05 \\
$\mathrm{r}^{2}$ & +19.67 & +2.16 \\
\hline
\end{tabular}

combination was found to be similar to that corresponding to $R_{7}$ and hence $R_{7}$ was treated as the optimized batch.

For particle size response, the Model F-value of 15.55 implies the model is significant. There is only a $2.35 \%$ chance that a "Model F-Value" this large could occur due to noise. $\mathrm{P}$ value were found to be 0.0235 , with a value less than 0.0500 indicating model terms are significant.

The "Predicted R-Squared" of 0.6033 is in reasonable agreement with the "Adjusted R-Squared" of 0.9009."Adeq Precision" measures the signal to noise ratio. A ratio greater than 4 is desirable. The ratio of 11.207 indicates an adequate signal thus the proposed model can be used to navigate the design space.

For \%EE response, the Model F-value of 26.66 implies the model is significant. There is only a $1.09 \%$ chance that a "Model F-Value" this large could occur due to noise. $\mathrm{P}$ value were found to be 0.0109 , with a value less than 0.0500 indicating model terms are significant.

The "Predicted R-Squared" of 0.7614 is in reasonable agreement with the "Adjusted R-Squared" of 0.9413."Adeq Precision" measures the signal to noise ratio. A ratio greater than 4 is desirable. The ratio of 12.862 indicates an adequate signal. Thus the proposed model can be used to navigate the design space.

Since the values of $\mathrm{r}^{2}$ are relatively high for both the responses, i.e., 0.9629 for particle size and 0.9780 for $\% \mathrm{EE}$, the polynomial equations form an excellent fit to the experimental data and are highly statistically valid.

Three-dimensional response surface plots for each response parameter were constructed to study the effects of both formulation variables simultaneously along with the behavior of the system.

Figure 1 shows response surface plot for particle size. It can be observed from the figure that drug: lipid ratio had a positive effect on particle size i.e. particle size 
increased with increase in drug: lipid ratio. Least particle size was observed at the lowest level of drug:lipid ratio. A greater amount of lipid may have resulted in increasing the size of SLN.

Sonication time had the opposite effect on particle size. It can be observed from Figure 1 that particle size decreased with increased sonication time. Figure 1 indicates that the sonication time had a greater impact on particle size compared to lipid content, moreover the effect of lipid content was more pronounced at a high level of sonication which might be due to less effort required to disperse the small lipid agglomerates. At low sonication time, lipid concentration had little influence.

Figure 2 shows simultaneous effect of sonication time and drug: lipid ratio on entrapment efficiency. It can be observed that EE increased with increased sonication time. Increased sonication time resulted in decreased particle size thereby increasing the total surface area and favoring entrapment. Drug: lipid ratio also had a similar effect. The value of EE was maximal when both formulation variables were employed at their highest levels. The reasons can be attributed to the maximum amount of lipid present for entrapment of the drug. The effect of sonication on entrapment was not evident at high lipid levels. At low lipid levels however, the decrease in sonication reduced entrapment which may be accounted for by less availability of lipid and decrease in lipid phase solubility of drug due to reduced sonication.

\section{Evaluation of solid lipid nanoparticles}

\section{Particle size analysis}

The d (90) for nanoparticulate dispersions showed a size ranging from $219-348 \mathrm{~nm}$ (Table III). The effect of lipid concentration on the particle size is evident from the particle size of samples $R_{3}, R_{6}$ and $R_{9}(342 \mathrm{~nm}, 319 \mathrm{~nm}$ and $285 \mathrm{~nm}$, respectively) where it is at high level and sonication time is at low, middle and low levels. Samples $\mathrm{R}_{4}$

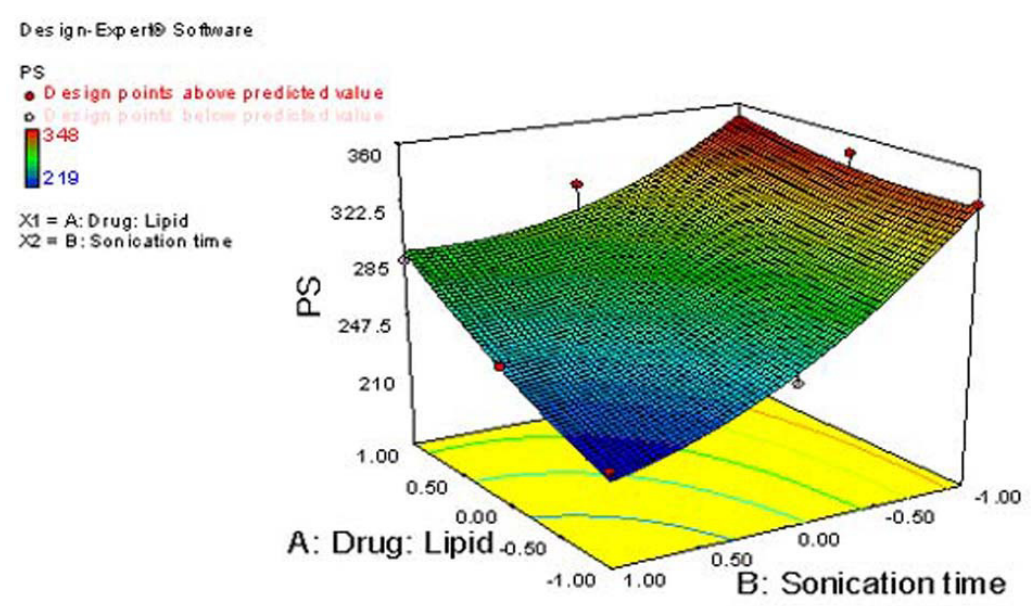

FIGURE 1 - Three-dimensional response surface plots for particle size.

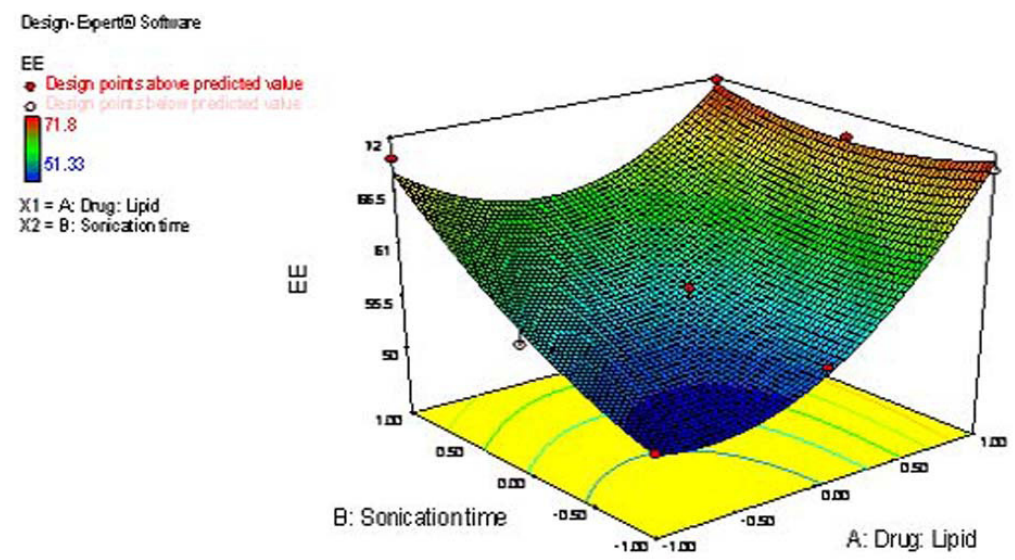

FIGURE 2 - Three-dimensional response surface plots for entrapment efficiency. 
and $\mathrm{R}_{7}$ with low lipid concentration (1:3) had the smallest particle size of between $200-300 \mathrm{~nm}$. The sonication time shows a negative influence on particle size. Particle size distribution of the optimized batch is shown in Figure 3.

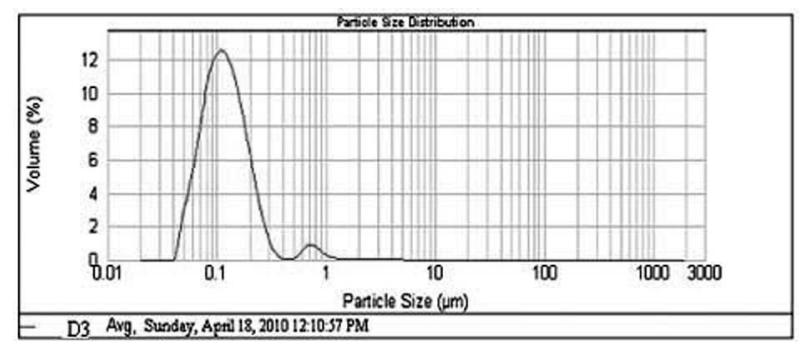

FIGURE 3 - Particle size distribution curve of optimized batch.

The second population of particles, as shown in the above figure, may be due to inadequate sonic energy at the periphery of the dispersion or to particle growth during the time period between sonication and size analysis.

\section{Entrapment efficiency}

A high amount of drug was incorporated in nanoparticle dispersion. The $\% \mathrm{EE}$ of different formulations prepared (Table III) indicates the positive influence of lipid content on drug entrapment. The formulations $\mathrm{R}_{3}$, $\mathrm{R}_{6}$ and $\mathrm{R}_{9}$ which have lipids at high level but surfactant at low middle and high levels, respectively showed \% entrapment of 70.3, 69.5 and 71.80 , respectively. This indicates overwhelming influence of lipid on entrapment, irrespective of surfactant content. Formulations $\mathrm{R}_{1}, \mathrm{R}_{4}$, which had lipid content at low level and surfactant at low and medium level, respectively show less $\% \mathrm{EE}(<60 \%)$. For formulation $\mathrm{R}_{7}$, the effect of high surfactant level was evident in the form of higher entrapment (69.88\%). The partitioning of drug between lipid and water phases during pre-emulsion formation affects drug entrapment in nanoparticles. This in turn depends on the amount of lipid, solubility of drug in lipid, process temperature and surfactant concentration. Therefore, the positive influence of lipid content on entrapment is explained.

\section{Differential scanning calorimetry}

The DSC technique was employed to characterize the DTH-loaded SLN. DSC thermograms (Figure 4) indicate the melting points and corresponding enthalpies of DTH, Compritol and SLN. The enthalpy indicates absolute heat energy uptake and is given by the area under the transition peak. The sharp melting endotherm of DTH was observed at $182.10^{\circ} \mathrm{C}$ with corresponding enthalpy of $-35.43 \mathrm{~J} / \mathrm{g}$ while compritol bulk showed a melting endotherm at $75^{\circ} \mathrm{C}$ and enthalpy of $-98.64 \mathrm{~J} / \mathrm{g}$. The DTH SLN showed an endothermic peak at $72.11^{\circ} \mathrm{C}$ and enthalpy of $-65.61 \mathrm{~J} / \mathrm{g}$. A shoulder peak was also observed alongside at $59.1^{\circ} \mathrm{C}$. In general, melting point depression is observed when the bulk lipid is transformed to nanoparticulate form. The decrease in melting point and formation of a shoulder peak is attributed to smaller particle size, lattice defects and formation of amorphous regions arising out of incorporation of drug molecules (Chen, et al., 2006; Schubert, Mu"ller-Goymann, 2005). This leads to the corresponding decrease in enthalpy from -98.64 to $-65.61 \mathrm{~J} / \mathrm{g}$.

\section{$X$-ray diffraction}

$\mathrm{X}$-ray diffraction data listed in the following Figure 5 was in good agreement with results established by DSC measurements. The diffraction pattern of the bulk matrix showed a marked difference from those of the SLN, as they showed a relatively sharper peak than the SLN. It was clear that from DTH-loaded SLN, the less ordered crystals were the majority and the amorphous state contributed to the higher drug loading capacity as seen previously. There was a significant difference between the diffraction patterns of dithranol and DTH-loaded SLN. It was confirmed that DTH existed in amorphous state in the DTH-SLN because of the disappeared sharp peak of DTH in the diffraction pattern.

\section{FTIR studies}

From FTIR study, the characteristic peak of drug such as of the aromatic $\mathrm{C}=\mathrm{O}\left(1597 \mathrm{~cm}^{-1}\right)$, aliphatic $\mathrm{C}-\mathrm{OH}$ $\left(2923 \mathrm{~cm}^{-1}\right)$, aromatic C-H $\left(731,773\right.$ and $\left.1459 \mathrm{~cm}^{-1}\right)$ disappeared and were replaced by the peak of compritol 888 ATO where remaining peaks also either shifted or were replaced in the IR spectrum of the formulation shown in Figure 6. This established drug entrapment in lipid matrix.

\section{Ex-vivo skin penetration studies}

The ex-vivo permeation of DTH through rat skin from DTH-loaded SLN ointment was evaluated using a Franz diffusion cell. The mean cumulative amount diffused $\mathrm{Q}\left(\mathrm{mg} / \mathrm{cm}^{2}\right)$ at each sampling time point was calculated. The results of diffusion studies are represented graphically as Q vs Time in Figure 7.

In the present investigation, DTH-loaded SLN ointment of optimized formulation produced significantly higher deposition of DTH in skin (55\%) than marketed Ointment of DTH (27\%), as shown in Table V. The stratum corneum which represents the principle barrier of skin structure has pore diameters of about $20 \mathrm{~nm}$ but in fully hydrated state the pore diameters increase to $400 \mathrm{~nm}$. Thus, a drug-localizing effect in the skin seems possible because of hydration of skin by an occlusion effect of 


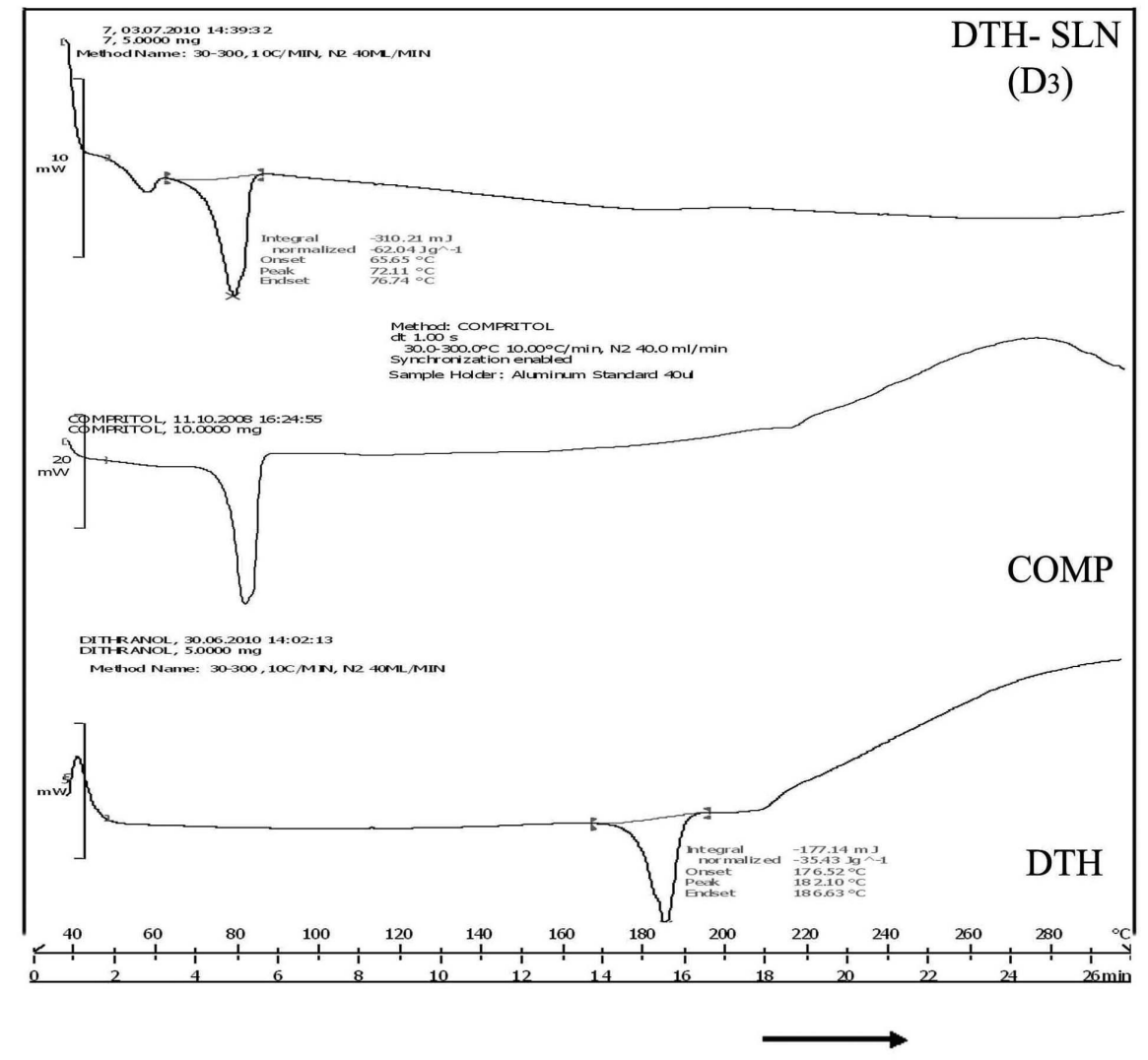

FIGURE 4 - DSC thermogram of DTH, Compritol ATO 888 and DTH-loaded SLN.

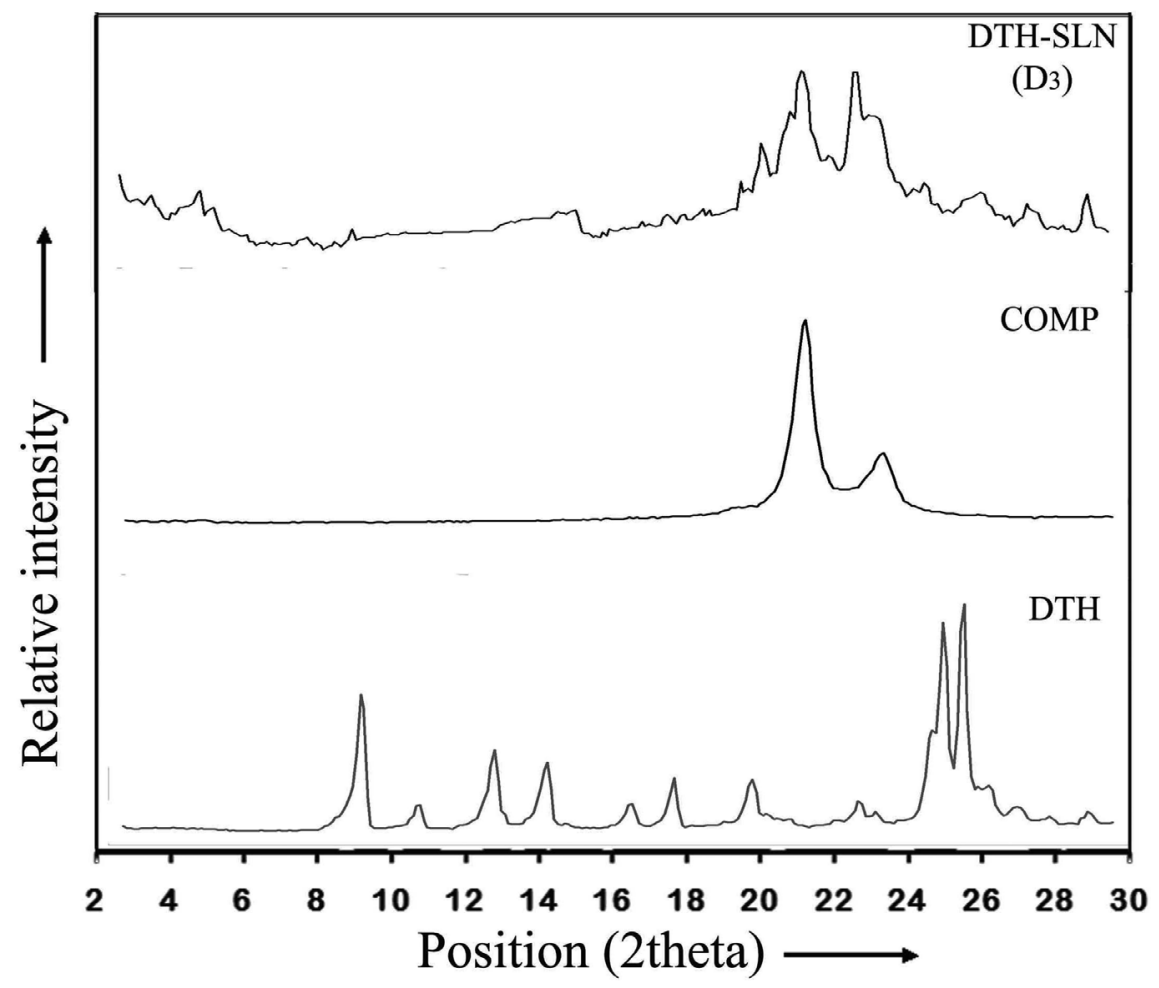

FIGURE 5 - XRD of dithranol, Compritol ATO 888 and DTH-loaded SLN. 


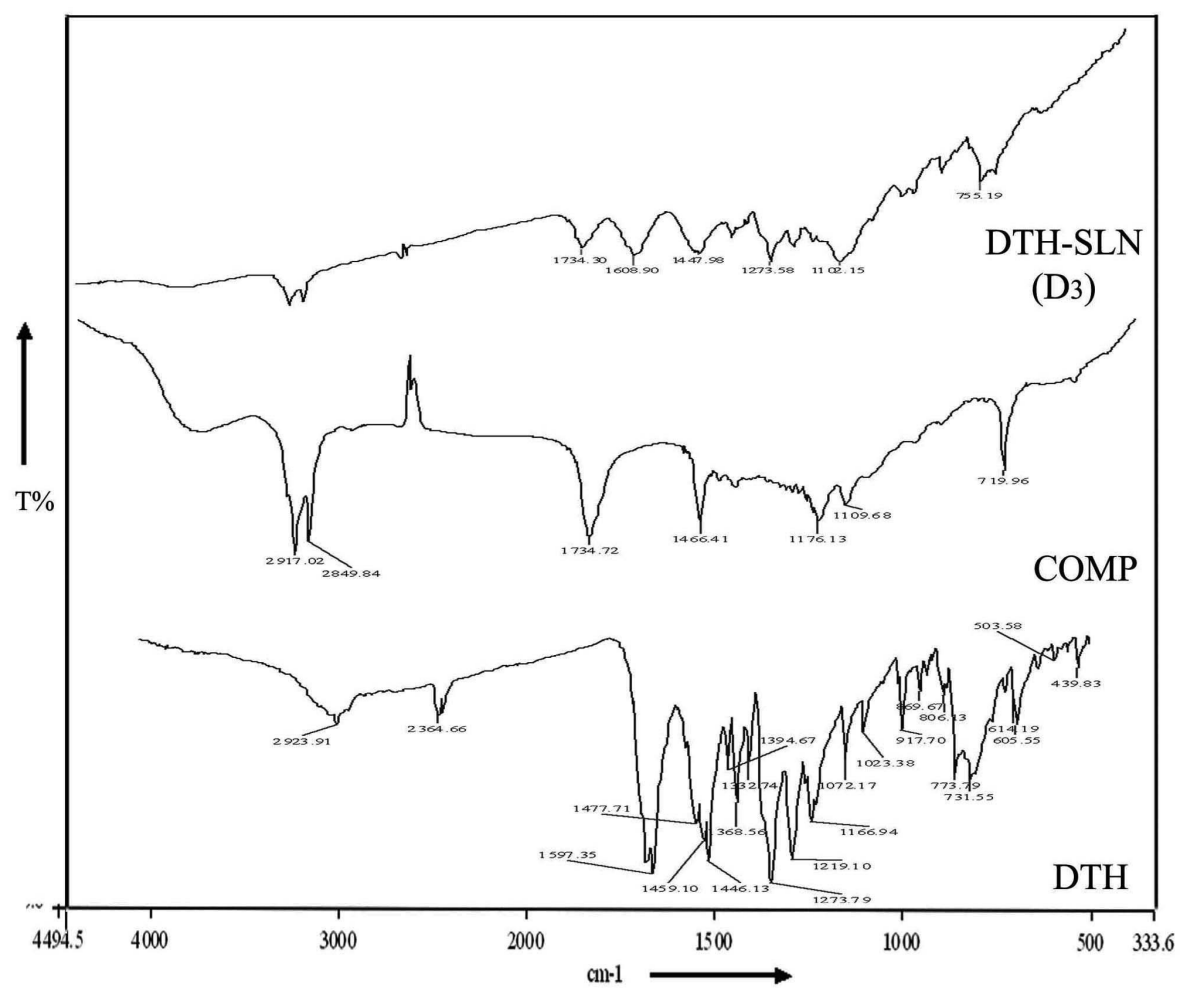

FIGURE 6 - IR spectra of dithranol, Compritol ATO 888 and DTH-loaded SLN.

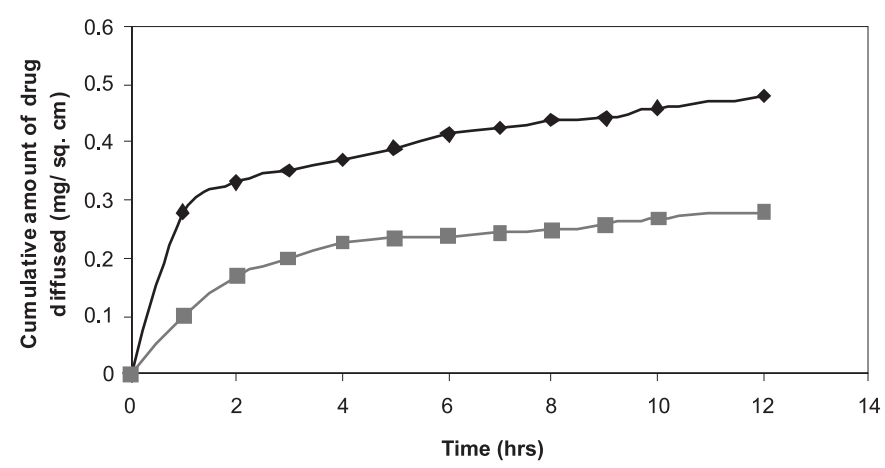

FIGURE 7 - Mean cumulative amount of drug diffused through rat skin. $\square$ DTH SLN ointment $\downarrow$ DTH Marketed ointment.

SLN, submicron particle size $(219 \mathrm{~nm})$ and high adhesion due to very high surface may explain the increase in skin permeation of dithranol SLN. Due to the lipoidal nature of SLN, the penetrated drug concentrates in the skin and remains localized for a longer period of time, thus enabling drug targeting for the skin (Pople, Singh, 2006).

\section{CONCLUSION}

The pre-emulsion followed by ultrasonication technique was used to prepare solid lipid nanoparticles of reproducible sizes in the range of 219 to $348 \mathrm{~nm}$ by addressing the effects of processing parameters. The ap-
TABLE V - Mean amount of dithranol deposited in Rat skin and remaining on the skin

\begin{tabular}{|c|c|c|}
\hline $\begin{array}{l}\text { Test } \\
\text { formulation }\end{array}$ & $\begin{array}{c}\text { Rat skin }(\%) \\
\text { mean }( \pm \text { SEM })\end{array}$ & $\begin{array}{c}\text { DTH remaining on } \\
\text { the skin }(\%) \\
\text { Mean }( \pm \text { SEM })\end{array}$ \\
\hline Marketed DTH ointment & $27 \pm 3.69$ & $44 \pm 2.53$ \\
\hline DTH-SLN ointment & $55 \pm 2.23$ & $25 \pm 1.87$ \\
\hline
\end{tabular}

plication of $3^{2}$ factorial design proved to be a useful tool for optimization of DTH-loaded SLN. Using the factorial design one can select a suitable composition of formulation to obtain DTH-loaded SLN in the size range of 219 to $348 \mathrm{~nm}$ depending on the application of the system. The results of the ex-vivo penetration studies demonstrated that about a two-fold increase in localization of DTH in skin was obtained with DTH-loaded SLN entrapped ointment compared to plain DTH.

\section{REFERENCES}

CHEN, H.B.; CHANG, X.L.; YANG, X.L.; DU, D.R.; LIU, W.; LIU, J.; WENG, T.; YANG, Y.J.; XU, H.B. Podophyllotoxinloaded solid lipid nanoparticles for epidermal targeting. $J$. Control. Rel., v.110, p.296-306, 2006. 
FANG, J.U.; FANG, C.L.; LIU, C.H.; SU, Y.H. Lipid nanoparticles as vehicles for topical Psoralen delivery:Solid lipid nanoparticles (SLN) versus nanostructured lipid carriers (NLC). Eur. J. Pharm. Biopharm., v.70, p.633640, 2008.

GERRITSEN, M. J. P. Dithranol. In: KERKHOF, P. V. (Ed.) Textbook of psoriasis. 2.ed. Oxford: Blackwell Publishers, 2007. p.172-184.

LIU, J.; HU, W.; CHEN, H.; NI, Q.; XU, H.; YANG, X. Isotretinoin-loaded solid lipid nanoparticles with skin targeting for topical delivery. Int. J. Pharm. v.328, p.191195, 2007.

LOWES, M.A.; BOWCOCK, A.M.; KRUEGER, J.G. Pathogenesis and therapy of psoriasis. Nature, v.445, p.866873, 2007.

LV, O.; YU, A.; XI, Y.; LI, H.; SONGA, Z.; CUI, J.; CAO, F.; ZHAI, G. Development and evaluation of penciclovirloaded solid lipid nanoparticles for topical delivery. Int. J. Pharm., v.372, p.191-198, 2009.

MAIA, C.S.; MEHNERT, W.; SCH“AFER-KORTING, M. Solid lipid nanoparticles as drug carriers for topical glucocorticoids. Int. J. Pharm., v.196, p.165-167, 2000.

MEI, Z.; CHEN, H.; WANG, T.; YANG, Y.; YANG, X. Solid lipid nanoparticle and microemulsion for topical delivery of triptolide. Eur. J. Pharm. Biopharm. v.56, p.189-196, 2003.

MÜLLER, R.H.; LIPPACHER, A.; GOHLA, S. Solid lipid nanoparticles (SLN) as a carrier system for the controlled release of drugs. In: WISE, D. (Ed.). Handbook of pharmaceutical controlled release technology. New York: Marcel Dekker, 2000. p.377-392.

MÜLLER, R.H.; MÄDER, K.; GOHLA, S. Solid lipid nanoparticles (SLN) for controlled drug delivery - review of the state of the art. Eur. J. Pharm. Biopharm. v.50, p.161$177,2000$.
MÜLLER, R.H.; MEHNERT, W.; LUCKS, J.S.; SCHWARZ, C.; ZUR MÜHLEN, A.; WEYHERS, H.; FREITAS, C.; RÜHL, D. Solid lipid nanoparticles (SLN) - an alternative colloidal carrier system for controlled drug delivery. Eur. J. Pharm. Biopharm. v.41, p.62-69, 1995.

MÜLLER, R.H.; RÜHL, D.; RUNGE, S.; SCHULZEFORSTER, K.; MEHNERT, W. Cytotoxicity of solid lipid nanoparticles as a function of the lipid matrix and the surfactant. Pharm. Res. v.14, p.458-462, 1997.

POPLE, P.V.; SINGH, K.K. Development and Evaluation of Topical Formulation Containing Solid Lipid Nanoparticles of Vitamin A. AAPS PharmSciTech., v.7, p.91, 2006.

SCHUBERT, M.A.; MU"LLER-GOYMANN C.C. Characterization of surface-modified solid lipid nanoparticles (SLN): Influence of lecithin and nonionic emulsifier. Eur. J. Pharm. Biopharm. v.61, p.77-86, 2005.

SHAH, K. A.; DATE, A. A.; JOSHI, M. D.; PATRAVALE, V. B. Solid lipid nanoparticles (SLN) of tretinoin: potential in topical delivery. Int. J. Pharm. v.345, p.163-171, 2007.

SIVARAMAKRISHNAN, R.; NAKAMURA, C.; MEHNERT, W.; KORTING, H.C.; KRAMER, K.D.; SCH“AFERKORTING, M. Glucocorticoid entrapment into lipid carriers - characterization by parelectic spectroscopy and influence on dermal uptake. J. Control. Release. v.97, p.493-502, 2004.

SYLVIA, A.; M“ULLER, R. H.; WISSING, S. A. Cosmetic applications for solid lipid nanoparticles (SLN). Int. J. Pharm., v.254, p.65-68, 2003.

TUCKER, W. F. G.; MAC NEIL, S.; DAWSON, R. A.; TOMLINSON, S.; BLEEHEN, S. S. An investigation of the ability of antipsoriatic drugs to inhibit calmodulin activity: a possible mode of action of dithranol (anthralin). J. Investigative Dermat. v.87, p.232-235, 1986.

UTREJA, S.; JAIN N.K. Solid lipid nanoparticles. In: JAIN, N.K. (Ed.). Advances in controlled and novel drug delivery. New Delhi, India: CBS Publishers, 2001. p.408-425.

Received for publication on $9^{\text {th }}$ December 2010 Accepted for publication on $22^{\text {nd }}$ March 2011 
